\section{Japan's whaling is unscientific}

Japanese whalers are back in the Southern Ocean, aiming to kill 333 minke whales - ostensibly for the purposes of scientific research - under special permits issued by their government. In our view, the science behind Japan's whaling activity has not passed a reasonable standard of peer review.

We are members of the International Whaling Commission's Scientific Committee (IWC-SC), plus one independent expert witness (M. Mangel) whose evidence contributed to the March 2014 negative ruling on Japan's JARPA II whaling permit by the International Court of Justice (ICJ; see A.S. Brierley Nature 520, 157; 2015). In 2015, Japan submitted a new whaling proposal (NEWREP-A). The IWC-SC coordinated two rounds of review, including one by an independent expert panel that concluded that lethal sampling had not been justified. Numerous IWC-SC members recommended exploration of widely used non-lethal alternatives (see, for example, A. M. Polanowski et al. Mol. Ecol. Resour. 14, 976-987; 2014) before killing is resumed.

Japan claims to have "sincerely taken into account" the IWC-SC's opinion, but, as on previous occasions, has failed to alter its plans in any meaningful way and is proceeding to kill whales under a self-determined quota. In October 2015, Japan also rejected the jurisdiction of the ICJ on this issue.

We believe that further discussion of special-permit whaling at IWC-SC under the present procedure - in which the opinion of proposers is afforded equal weight to that of referees - is a waste of time. The IWC urgently needs to develop a process of scientific review that results in clear decisions that can be respected by all.

Andrew S. Brierley ${ }^{\star}$ University of St Andrews, UK.

Phillip J. Clapham Alaska Fisheries
Science Center, Seattle, USA. asb4@st-andrews.ac.uk

${ }^{\star}$ Supported by 30 signatories (listed at go.nature.com/tfb6hp).

\section{No myth: benefits of breast screening}

Your attempt to debunk the "myth" that cancer screening saves lives is ill-conceived for breast cancer (Nature 528, 322-325; 2015). Women should be aware of the benefits and potential harms of breast screening, including that it can reduce the chance of death from breast cancer.

You cite one randomized screening trial that showed no reduction in deaths due to breast cancer. However, an independent meta-analysis of 11 trials, including the one you cite, demonstrates an overall $20 \%$ reduction in mortality (M. G. Marmot et al. Lancet 380, 1778-1786; 2012).

Further analysis reveals that only those trials that reduced the incidence of advanced disease (stage II or higher) produced lower mortality (L. Tabár et al. Breast J. 21, 13-20; 2015). This correlation supports the idea that reducing the incidence of advanced breast cancer by using other screening methods might reasonably be expected to reduce mortality. For example, combining mammography with magnetic resonance imaging reduces the chance that women who have a high breast-cancer risk will be diagnosed with late-stage disease (E. Warner et al. J. Clin. Oncol. 19, 3524-3531; 2001).

Screening is also beneficial because early detection reduces the need for mastectomy and chemotherapy. As treatments become more effective, the mortality benefit from screening might be anticipated to decline, but the other benefits will remain. Jeremy M. Berg, Wendie A. Berg University of Pittsburgh, Pennsylvania, USA.

jberg@pitt.edu

\section{No myth: population rise unsustainable}

You correctly point out that exponential human population growth is a myth (see Nature $\mathbf{5 2 8}, 322-325 ; 2015)$. The rate of growth has been slowing since 1970, largely as a result of education efforts aimed at women and girls, and family planning programmes. Population growth is still a serious concern, however, because human numbers and increases are currently unsustainable.

Ecological footprint analysis, for example, indicates that it would take 1.6 Earths to support the current world population at average resource-consumption levels (go.nature.com/xyohus). This is set to increase, given the expanded rate of consumption to which developing countries aspire. Moreover, we are tearing the web of life by condemning tens of thousands of non-human species to extinction (G. Ceballow et al. Sci. Adv. 1, e1400253; 2015). A positive rate of growth will make the damaging effects of the human population to our planet even worse.

Richard E. White ${ }^{\star}$ Durango,

Colorado, USA.

rwhite@gobrainstorm.net

${ }^{*}$ On behalf of 4 correspondents (see go.nature.com/kueb3g for full list).

\section{Language ruling stymies brain gain}

Even a Nobel laureate would now be unlikely to be appointed to the science teaching faculty in many of Spain's best universities. This absurd situation is a result of tenure-track positions becoming conditional on a fluency in Spanish and/or the university's regional language. The restriction, intended to promote local languages, shatters any hope of attracting brilliant minds from abroad into our system.

The national call for 2016 predoctoral fellowships, Spain's only public scheme for funding $\mathrm{PhD}$ candidates, also demands that applicants have an intermediate diploma in Spanish or in the official regional language.

We do not question the need to protect all of our languages, which are an important part of our culture. But science is a realm in which content should take precedence over form, the 'what' over the 'how'. We should instead be following the lead of other universities in providing language tuition, if necessary, once a post is taken up.

Spain cannot afford further gambits with its science, which is already seriously compromised by the international financial crisis and questionable shortterm science policies.

Pau Carazo, Enrique Font University of Valencia, Spain. pau.carazo@uv.es

\section{Water scheme acts as ecological buffer}

We disagree with Jon Barnett and colleagues that China's South-to-North Water Diversion (SNWD) project marks a low point for big engineering solutions to the country's water problems (Nature 527, 295-297; 2015). The SNWD conveyed 8.37 billion cubic metres of water ( 6.20 billion by the eastern route; 2.17 billion by the central route) to millions of people in northern China by the end of 2015. It is also acting as a buffer against imminent ecological disaster and social upheaval.

It will take time to educate the public about water consumption and to implement the reforms to agricultural and industrial production that the authors propose. The 'sponge city' programme to harvest rainwater and recycle wastewater is also likely to be costly and disruptive. Meanwhile, the SNWD is providing the material foundations necessary for well coordinated water management. Han Lin, Saixing Zeng, Hanyang Ma Shanghai Jiao Tong University, Shanghai, China. zengsaixing@sjtu.edu.cn 